\title{
Aortic Aneurysm in Hemodialysis Patients: A Report of Two Cases
}

\author{
Befa Noto Kadou Kaza ${ }^{1}$, Kossi Akomola Sabi ${ }^{2}$, Ali Hissein Mahamat ${ }^{1}$, \\ Yasminatou Aminata Wendkuuni Bikinga ${ }^{1}$, Mays Hadi Al Torayhi ${ }^{1}$, \\ Eyram Yoan Makafui Amekoudi ${ }^{2}$, Comlan Mawuko Blitti ${ }^{3}$, Keyit Leonard Yegha ${ }^{2}$, \\ Ghislaine Medkouri ${ }^{1}$, Mohamed Gharbi Benghanem ${ }^{1}$, Benyounes Ramdani ${ }^{1}$ \\ ${ }^{1}$ Department of Nephrology, Dialysis and Kidney Transplantation of IbnRochd University Hospital, Casablanca, Morocco \\ ${ }^{2}$ Department of Nephrology, Dialysis of Sylvanus Olympio University Hospital, Lome, Togo \\ ${ }^{3}$ Department of Vascular, Surgery of University Hospital, Fes, Morocco
}

Email address:

bfanotokadoukaza@yahoo.fr (Befa N. K. K.)

\section{To cite this article:}

Befa Noto Kadou Kaza, Kossi Akomola Sabi, Ali Hissein Mahamat, Yasminatou Aminata Wendkuuni Bikinga, Mays Hadi Al Torayhi, Eyram Yoan Makafui Amekoudi, Comlan Mawuko Blitti, Keyit Leonard Yegha, Ghislaine Medkouri1, Mohamed Gharbi Benghanem, Benyounes Ramdani. Aortic Aneurysm in Hemodialysis Patients: A Report of Two Cases. American Journal of Internal Medicine. Vol. 3, No. 4, 2015, pp. 153-155. doi: 10.11648/j.ajim.20150304.11

\begin{abstract}
Introduction: Aortic aneurysm (AA) is a frequent pathology in the general population. Patients at risk are those who have factors that can lead to arterial degeneration mainly high blood pressure (HBP), smoking and inflammation. In patients with chronic kidney failure (CKF) especially those who undergo hemodialysis who have almost all these risk factors, very little attention on the study of AA is accorded them. We reported two cases of AA in hemodialysis patients. Observation: Case 1. Fifty two (52) years old male, with past history of HBP since 21years of age, declared to have a terminal CKF from an undetermined nephropathy that has been on hemodialysis since 15 years. After 6 years of hemodialysis he presented an acute coronary syndrome associated with a painful abdominal syndrome which led to the diagnosis of aneurysm of the ascending aorta that measured $5 \mathrm{~cm}$ in diameter. Therapeutic abstinence was adopted with annual follow up using chest angio-CT scan and thrombosis prevention using platelet aggregation inhibitors. The lesion is stable since 9 years. Case 2. Forty two (42) years old male, with no particular past history. Terminal CKF from an undetermined nephropathy that has been on hemodialysis since 6 years. On the $5^{\text {th }}$ year of hemodialysis he presented a painful abdominal syndrome with no gas no food passage that lead to the diagnosis of abdominal aorta aneurysm of $4.7 \mathrm{~cm}$ diameter and a height of $12 \mathrm{~cm}$. Atherapeutic abstinence was adopted with follow up and anti thrombolytic therapy put. After one year of evolution, the patient developed a mesenteric artery ischemia that on exploration showed a fissuration of the aneurysm that lead to the death of the patient. Conclusion: Aortic aneurysm in CKF has been a concerned in patients who had in most cases polycystic kidney disease who were not yet on hemodialysis. AA is a reality in patients on hemodialysis. Its evolution is uncertain and at times it is fatal. Screening for it is obligatory.
\end{abstract}

Keywords: Aneurysm, Aorta, Hemodialysis

\section{Introduction}

Aortic aneurysm (AA) is a frequent pathology. Its prevalence in the general population is estimated at between 3 and $4 \%$ and it can go up to $7 \%$ in patients who are more than 65 years of age. Various possible etiologies of AA are degenerative process that wipes out the connective tissue, inflammatory diseases, genetic factors, infectious causes. Risk factors include advanced age, male sex, family history of AA,
HBP, hypercholesterolemia, smoking, atherosclerosis (1-9). The initial development and growth of AA is as a result of a complex interaction of these factors. In general, chronic kidney failure (CKF) and particularly hemodialysis patients have a multitude of these risk factors. This will normally lead to a high prevalence of AA in such patients. Though very little data is found on AA in hemodialysis patients. We are reporting two cases of AA in hemodialysis patients, one concerns the ascending aorta and the other the abdominal aorta. 


\section{Observation}

Case 1. Fifty two (52) years male, with a past history of HBP since twenty one (21) years of age that was poorly managed, declared to have a terminal CKF from an undetermined nephropathy that was put on periodic hemodialysis since 15 years. After 6 years of hemodialysis, he presented an acute coronary syndrome associated with a painful abdominal syndrome. Exploration with abdominal ultrasound and CT scan angiography led to the diagnosis of a fusiform aneurysm of the ascending aorta that measured $5 \mathrm{~cm}$ in diameter. Therapeutic abstinence was adopted with annual follow up using chest angio-CT scan and thrombosis prevention using platelet aggregation inhibitors. The lesion is stable since 9 years. In addition this patient has a chronic biological inflammatory syndrome.

Case 2. Forty two (42) years old male, with no particular past history terminal CKF from an undetermined nephropathy that has been on periodic hemodialysis since 6 years. On the $5^{\text {th }}$ year of hemodialysis, he presented a painful abdominal syndrome with no gas no food passage that lead to the diagnosis of abdominal aorta aneurysm of $4.7 \mathrm{~cm}$ diameter and a height of $12 \mathrm{~cm}$. The patient had no biological inflammatory syndrome. A therapeutic abstinence was adopted with radiological follow up and anti thrombolytic therapy put. After one year of evolution, the patient developed a mesenteric artery ischemia that on exploration showed a fissuration of the aneurysm that lead to the death of the patient before surgical intervention could be done.

\section{Discussion}

Though AA is a frequent affection, in the general population and that most of the risk factors are found in patients with CKF, mainly those who do hemodialysis (1-9), epidemiologic data on AA in hemodialysis is rare. The most common found data concerns kidney complication after operations for AA in patients whose kidneys preoperatively were normal or were slightly altered. Here the post operative incidence of kidney failure for AA is $5.4 \%$ in patients with a normal kidney function; this incidence is multiplied by 2 or 3 amongst patients with a pre existing CKF (10-12). Mortality after kidney complication due to AA operation is very high and $25 \%$ to $66 \%(10-12)$. There is almost no data on the incidence and the prevalence of AA in hemodialysis patients. Very few reported cases concern patients who have an autosomal dominant polycystic kidney gene and are on hemodialysis (13-15). In our centre we isolated two cases out of 98 (98\%) who presented AA. One concerned the ascending aorta and the other, the abdominal aorta. One of the patients had a past history of HBP and a biological inflammatory syndrome. The second patient had no risk factor for AA except for the fact that he was on hemodialysis. Anyway, a patient with chronic kidney failure in general and hemodialysis in particular constitute a high cardiovascular risk and seems to be the cause of AA in the second patient. The circumstance of diagnosis was just like in the general population. In the 02 patients therapeutic abstention was adopted because the diameter was less than $6 \mathrm{~cm}(<6 \mathrm{~cm})$. With a high post operative mortality in this type of patients, very few AA are operated (16-17). The evolution of the first patient is very good till date after 9 years of follow up. Meanwhile it was fatal in the second in less than a year confirming the seriousness of this affection in hemodialysis patients be it operated or not.

\section{Conclusion}

Aortic aneurysm in hemodialysis is a reality. Its diagnosis is not specific just like its management. But its evolution is uncertain and at times fatal. Patients who are on hemodialysis should be included in a screening program for its early management.

\section{References}

[1] Rodin MB, Daviglus ML, Wong GC, Liu K, Garside DB, Greenland P, Stamler J. Middle age cardiovascular risk factors and abdominal aortic aneurysm in older age. Hypertension 2003; 42:61-68.

[2] Blanchard JF, Armenian HK, Friesen PP. Risk factors for abdominal aortic aneurysm: results of a case-control study. Am J Epidemiol. 2000; 151: 575-583.

[3] Franks PJ, Edwards RJ, GreenhalghRM, Powell JT. Risk factors for abdominal aortic aneurysms in smokers. Eur J VascEndovasc Surg. 1996; 11: 487-492.

[4] Hobbs SD, Claridge MW, Quick CR, Day NE, Bradbury AW, Wilmink AB. LDL cholesterol is associated with small abdominal aortic aneurysms. Eur J VascEndovascSurg. 2003; 26: $618-622$.

[5] Lee AJ, FowkesFG, Carson MN, Leng GC, Allan PL. Smoking, atherosclerosis and risk of abdominal aortic aneurysm. Eur Heart J.1997; 18:671-676.

[6] Singh K, BonaaKH, Jacobsen BK, Bjork L, Solberg S. Prevalence of and risk factors for abdominal aortic aneurysms in a population-based study: the Tromso Study. Am J Epidemiol. 2001;154:236-244.

[7] Tornwall ME, Virtamo J, HaukkaJK, Albanes D, HuttunenJK. Life-style factors and risk for abdominal aortic aneurysm in a cohort of Finnish male smokers. Epidemiology. 2001;12:94100 .

[8] Vardulaki KA, Walker NM, Day NE, Duffy SW, Ashton HA, Scott RA. Quantifying the risks of hypertension, age, sex and smoking in patients with abdominal aortic aneurysm. Br J Surg. 2000;87:195-200.

[9] Al-Omran M., Verma S., Lindsay T.F., Weisel R.D., Sternbach Y. Clinical Decision Making for Endovascular Repair of Abdominal Aortic Aneurysm Circulation 2004; 110: e517e523 (Serie Clinical Update).

[10] Johnston KW. Multicenter prospective study of nonruptured abdominal aortic aneurysms. II: Variables predicting morbidity and mortality. J VascSurg 1989; 9: 437-47. 
[11] Joseph MG, McCollum PT, Lusby RJ. Abnormal preoperative creatinine levels and renal failure following abdominal aortic aneurysm repair. Aust N Z J Surg 1989; 59: 539-41.

[12] Atsushi Guntani, JyunOkadome, EisukeKawakubo, Ryoichi Kyuragi, Kazuomilwasa, RyotaFukunaga, SoseiKuma, Takuya Matsumoto, Jin Okazaki,and Yoshihiko Maehara, Clinical Results of Endovascular Abdominal AorticAneurysm Repair in Patients with Renal Insufficiency without Hemodialysis Ann Vasc Dis Vol.5, No.2; 2012; pp 166-171

[13] Takagi H, Umemoto T. Abdominal aortic aneurysm and autosomal-dominant polycystic kidney disease. Kidney Int 2005;67:376.

[14] Kato A, Takita T, Furuhashi M, Maruyama Y, Hishida A. Abdominal aortic aneurysms in hemodialysis patients with autosomal dominant polycystic kidney disease. Nephron 2001;88:185-6.

[15] Nacasch N, Werner M, Golan E, Korzets Z. Arterial dissections in autosomal dominant polycystic kidney diseasechance association or part of the disease spectrum? Clin Nephrol 2010;73:478-81

[16] GajdosC, Hawn MT, Kile D, Henderson WG, Robinson T, McCarter M, Nehler MThe risk of major elective vascular surgical procedures in patients with end-stage renal disease.Ann Surg. 2013;257(4):766-73.

[17] Yuo TH, Sidaoui J, Marone LK, Avgerinos ED, Makaroun MS, Chaer RA. Limited survival in dialysis patients undergoing intact abdominal aortic aneurysm repair. J Vasc Surg. 2014;60(4):908. 